\title{
Article
}

\section{How equitable is vocational rehabilitation in Sweden? A review of evidence on the implementation of a national policy framework}

Burstrom, Bo, Nylen, Lotta, Clayton, Stephen and Whitehead, Margaret

Available at http://clok.uclan.ac.uk/11106/

Burstrom, Bo, Nylen, Lotta, Clayton, Stephen ORCID: 0000-0003-2823-1495 and Whitehead, Margaret (2011) How equitable is vocational rehabilitation in Sweden? A review of evidence on the implementation of a national policy framework. Disability and Rehabilitation, 33 (6). pp. 453-466. ISSN 0963-8288

It is advisable to refer to the publisher's version if you intend to cite from the work.

For more information about UCLan's research in this area go to http://www.uclan.ac.uk/researchgroups/ and search for <name of research Group>.

For information about Research generally at UCLan please go to http://www.uclan.ac.uk/research/

All outputs in CLoK are protected by Intellectual Property Rights law, including Copyright law. Copyright, IPR and Moral Rights for the works on this site are retained by the individual authors and/or other copyright owners. Terms and conditions for use of this material are defined in the policies page. 


\title{
How equitable is vocational rehabilitation in Sweden? A review of evidence on the implementation of a national policy framework
}

\author{
BO BURSTROM ${ }^{1}$, LOTTA NYLEN ${ }^{1}$, STEPHEN CLAYTON ${ }^{2} \&$ MARGARET WHITEHEAD $^{2}$ \\ ${ }^{1}$ Department of Public Health Sciences, Division of Social Medicine, Karolinska Institutet, Stockholm, Srweden and ${ }^{2}$ Public \\ Health, University of Liverpool, Liverpool, UK
}

Accepted May 2010

\begin{abstract}
Purpose. Under the national framework law in Sweden, all eligible people should have equal chances of receiving vocational rehabilitation. We aimed to review the evidence on (1) whether access to vocational rehabilitation is equitable in practice and (2) whether the outcomes vary for different groups in the population.

Method. Systematic review of studies in Sweden that reported diagnostic or socio-demographic characteristics of people offered or taking up rehabilitation programmes and outcomes of such programmes for different diagnostic and sociodemographic groups. Searches of 11 relevant electronic databases, 15 organisational websites, citation searching and contact with experts in the field, for the period 1990-2009.

Results. A total of 11 studies were included in the final review, six of which addressed review question (1) and seven addressed review question (2). All the six observational studies of access reported biased selection into vocational rehabilitation: greater likelihood for men, younger people, those with longer-term sick leave, those with lower income, employed rather than unemployed people and those with musculoskeletal and mental disorders or alcohol abuse. Having had a rehabilitation investigation also increased the likelihood of receiving vocational rehabilitation. Differential outcome of rehabilitation was reported in seven studies: outcomes were better for men, younger people, employed individuals, those with shorter sick leave and those with higher income. Selection into vocational rehabilitation was perceived as important for successful outcomes, but success also depended on the state of the local labour market.

Conclusions. There is evidence of socio-demographic differences in access to and outcomes of vocational rehabilitation in Sweden, even though the national framework law is meant to apply to everyone. Few studies have deliberately measured differential access or outcomes, and there is a need for this kind of equity analysis of population-wide policies. Studies evaluating the effects of vocational rehabilitation must consider selection into the programmes for adequate interpretation of impact results.
\end{abstract}

Keywords: Social differentials, vocational rehabilitation, equity

\section{Introduction}

Many high-income countries are facing the problem of increasing numbers of working-age people outside the labour market due to chronic illness or disability [1]. In Sweden, almost $15 \%$ of the population of working age is outside the labour market due to illhealth. The total costs for the national social insurance system (sickness benefit, rehabilitation, activity payment and occupational injuries) were estimated to be SEK 113 billion in 2003 [2].

From an equity perspective, there is also evidence that the chances of being employed while having a chronic illness or disability decrease with decreasing socio-economic status $[3,4]$, raising concerns that inequalities in health may be generated or exacerbated by the differential impact of policies to get people back to work. Conversely, purposeful interventions in this field could theoretically be an entry point for reducing inequalities in health and in the social and economic consequences of disease. Very little is known, however, about the impact on employment and health of measures to increase economic activity rates for chronically ill or disabled people from different socio-economic groups. In a systematic review of the effectiveness of the UK's

Correspondence: Bo Burstrom, Department of Public Health Sciences, Division of Social Medicine, Norrbacka building, 2nd floor, Karolinska Institutet, Stockholm, SE 17176 Sweden. E-mail: bo.burstrom@ki.se 
welfare-to-work programmes for people classed as disabled or chronically ill, most studies were smallscale pilot schemes without a control group and none considered whether impacts differed by socio-economic group [5]. The UK review concluded that, conceptually, earlier preventive intervention, such as the Swedish policies of vocational rehabilitation, showed promise, and could yield useful lessons for other countries facing similar challenges [5].

We set out in this study to review the evidence on the workings of the national framework law on vocational rehabilitation in Sweden from an equity perspective. Because we are particularly interested in whether interventions help to tackle social inequalities in health and welfare, we asked questions about who gets access to such programmes and who benefits most in terms of return to work.

\section{The national policy context}

From the late 1980s and early 1990s onwards, a number of interventions were initiated in Sweden, to prevent work-related sickness absence and to facilitate return to work of people on long-term sickness absence [6,7]. Recognition of a lack of coordination between relevant agencies and actors involved in rehabilitation triggered a number of large-scale coordination programmes (FINSAM, FRISAM and SOCSAM), which led to several trial projects [6-8]. In the early 1990s, the Working Life Fund invested SEK 11 billion to improve the work environment, through 25,000 different projects [9]. Although generally perceived as positive, the effects of these initiatives have rarely been formally evaluated $[8,10]$.

From the end of the 1990s, long-term sick leave in Sweden increased dramatically, particularly among women, and in the health care sector [2]. Despite levelling off from around 2003, rates of long-term sick leave remain high. Against this background, increased emphasis has been placed on vocational rehabilitation as a means of returning people to work. National social insurance legislation provides for equal access to vocational rehabilitation measures $[11,12]$ : all working-age individuals in Sweden (with a few exceptions) when on long-term sick leave have the possibility (but not the right) to receive vocational rehabilitation.

A person who becomes sick notifies his/her employer or local social insurance office and receives sickness benefits from their employer for the first 2 weeks and subsequently from the social insurance office. If sickness continues for more than 4 weeks, legislation stipulates that a rehabilitation investigation should be carried out. For employed people, it is the employer's duty to initiate this process, whereas for the unemployed it falls to the employment office. Employers have a duty to provide workplace rehabilitation, if possible; otherwise the local insurance office purchases rehabilitation measures from hospitals and private providers $[11,13,14]$. The primary aim of such programmes in the Swedish context is to aid the people on sick leave to restore or manage their lost working capacity and, in some cases, become independent of the welfare system [6]. Otherwise, disability pension is the last resort. The legislation and rules concerning sick leave have been altered through the years. One characteristic of the Swedish system has been that it has had no fixed time limit for how long a person may be on sick leave. This has however recently changed and since 1 July 2008, there is a time limit of 365 days [15].

There is no standard definition of vocational rehabilitation for the process laid down in law [16]. Frolich et al., however, identified five different types of rehabilitation intervention: workplace, comprising vocational work training in the current or a new workplace; educational, comprises educational training towards a new occupation; medical and social rehabilitation focus on restoring health and basic work capacity; passive, comprises assessments and needs evaluations to decide whether attempts to recover previous working capacity are economically and medically viable [13]. People on sick leave may undertake one or more of these rehabilitation measures.

The Swedish rehabilitation legislation is enacted as a framework law, allowing social insurance offices and individual officers' wide discretion in decisionmaking and action. This allows considerable differences in the choice of rehabilitation measure in different offices and in treatment and/or options offered to a person on sick leave $[12,17]$.

In a survey of Swedish rehabilitation strategies 1990-2006, Bergendorff [6] found that the strategies did not correspond to the need of today's working life. The distribution of responsibilities among rehabilitation actors was indistinct; no actor had the full responsibility for the individual's return to work; there were no economic incentives for success and no penalties for failure to take responsibility.

The Swedish social insurance system is currently undergoing considerable changes and reforms, aiming to reduce rates of long-term sick leave and to increase the rate of return of persons on sick leave to the labour market [18]. Hence, it appears timely and more important than ever to carry out equity assessments of policy of the kind reported here. The purpose of this study is to review the evidence on whether access to vocational rehabilitation is equitable in practice, and whether the outcomes vary for different groups in the population in Sweden. 


\section{Methods}

The study was undertaken as a systematic review aimed at identifying primary studies (experimental, observational and qualitative) that investigated differential access to, and differential outcome of, vocational rehabilitation in Sweden. The two review questions were:

1. Is there evidence of differential access to the vocation rehabilitation programmes for chronically ill or disabled people of working age provided in Sweden under the national framework law, and if so, what is the nature and extent of this differential access?

2. For those who gain access, is there evidence of differential outcomes of the Swedish rehabilitation programmes, and if so, what is its nature and extent?

Inclusion and exclusion criteria

For review question 1, we included primary studies of any design that reported the diagnosis and demographic or socio-economic characteristics of people who were offered and/or took up vocational rehabilitation in Sweden under the national policy framework. For review question 2, we included primary studies of any design that reported on the outcomes (employment, unemployment or disability pension) of such vocational rehabilitation programmes by diagnosis and demographic or socioeconomic characteristics of the participants. Studies were excluded if they did not report their findings for individuals or groups with different diagnoses and demographic or socio-economic characteristics. Only studies of working-age (16-65) people on long-term sick leave or unemployed due to their health condition were included; other age groups and health status categories were excluded. Studies in Sweden, published in Swedish or English between the years 1990 and 2009, were included; studies from other countries, in other languages or published outside the review period were excluded.

\section{Search strategy and review process}

Eleven electronic databases were searched for the years 1990-2009 for publications in English and Swedish, using terms developed in cooperation with the project team. The specific search terms and the search strategy are outlined in Appendix. In addition, manual searches and searches of 15 relevant organisational websites (listed in Appendix) were carried out; reference lists of retrieved articles were searched manually, and key experts in the field were contacted with requests for information on unpublished reports and other studies that they could identify.

The initial sifting of the results of the searches was carried out jointly by two reviewers, with disagreements brought to the wider team for discussion. The reviewers excluded clearly irrelevant titles and abstracts and retrieved full text copies of the remainder. All retrieved papers were evaluated for relevance by two reviewers in accordance with the inclusion and exclusion criteria drawn up by the authors. The study designs and datasets were critically appraised for their appropriateness and completeness in addressing one or the other review question. Beyond this appraisal, care was taken to consider the design and conduct of each study when interpreting the findings and to be properly cautious in inferring causation.

\section{Results}

The material obtained from database searches identified 648 titles and abstracts, which were reviewed for relevance to the review questions. A total of 37 studies were retrieved for detailed examination. Nine of these met the inclusion criteria. Two further studies, identified from searches of websites, met the inclusion criteria. A total of 11 studies that met the inclusion and exclusion criteria were therefore finally selected for review (Figure 1).

None of the studies identified had either of the two review questions as their main objectives. For review question 1 on the access to vocational rehabilitation, six observational studies [12,19-23] of populationbased or employee-based registers of people on sick leave in Sweden were included, in which their receipt of vocational rehabilitation was recorded and analysed by socio-economic, demographic or health characteristics of individuals. One study included a questionnaire survey [12], which examined informants' knowledge of bias in attitudes and practices regarding selection for VR under the Swedish national framework legislation.

For review question 2 on the differential outcomes of vocational rehabilitation, five observational studies over time [19,23-26] of people who had been on long-term sick leave were included. The study samples were drawn from official, population-based or employee-based registers of sick-listed individuals, which recorded who received vocational rehabilitation and who returned to work, and were analysed in terms of the characteristics of the people more or less likely to return to work afterwards. One study [26] with no comparison group followed-up the participants of a rehabilitation programme on completion of rehabilitation and again 1 year after completion, 
with internal comparison of factors determining success and stability of results over time. Another study was a before-and-after evaluation of a rehabilitation programme with return-to-work as a measured outcome, with no comparison group, containing an internal comparison of the characteristics of more and less successful participants [27]. One further study examined informants' knowledge of prior selection of participants into rehabilitation programmes [28].

The final number of papers reviewed was 11; however, two papers [19,23] studied both review questions and the number of reported studies therefore adds up to 13 .

\section{Is there differential access to rehabilitation?}

Six studies were identified that met the inclusion criteria and addressed review question 1 (see Table I). A register-based national study following-up some 15,000 long-term ( $>60$ days) sick leave cases in 1999, 2001 and 2003 for a maximum of 13 months found that the likelihood of starting vocational rehabilitation was increased for individuals aged $<55$ years, males, born in Sweden, employed, fulltime sick-listed, sick-listed by a company doctor, sick-listed due to mental disorders or musculoskeletal disease or alcohol abuse [19].

Another survey was part of a larger study on work and health in the public sector with a source population of 21,000 public employees in five municipalities and four county councils. A total of 776 individuals with an ongoing spell of sickness absence of 90 days or longer in 1999-2000 were identified and were sent a postal questionnaire on their experience of the vocational rehabilitation process. The response rate was $69 \%$ ( 484 women and $51 \mathrm{men}$ ). The majority (63\%) were in nursing/caring occupations, e.g. homebased carers, assistant nurses and childcare workers. Less than half had been in contact with the occupational health service or trade union based in the workplace. Half of the respondents who had received the legally required rehabilitation investigation by the employer after 8 weeks of the beginning of their sick leave were more likely to have been on rehabilitation programmes/vocational rehabilitation than those who have not had the required rehabilitation investigation, $68 \%$ and $41 \%$, respectively $(p<0.001)$, among women. Results were similar among men, but numbers were smaller [20].

In a study of all individuals on sick leave $(17,772$ cases) registered with six insurance offices in Gävleborg county in 1998-1999, substantial differences were found between offices in the proportion of individuals who received rehabilitation measures and the type of vocational rehabilitation received.
Less than $9 \%$ of sick-listed individuals ( 831 persons) received some form of rehabilitation measure, the proportion ranged between offices from 1.2 to $8.7 \%$. Among those receiving rehabilitation, the commonest measure was job training. Job training was more likely for women, whereas men were more likely to receive studies/education as rehabilitation [21].

A related study in 1998-1999 focused on the differences between the six local social insurance offices in the same county with regard to their selection of clients for vocational rehabilitation [12]. Thirty local social insurance officers responded to a survey questionnaire about their attitudes and practices regarding rehabilitation. There were wide differences in attitudes among the local social insurance officers and regarding professional practice in their application of the system, which may explain local differences in client selection and consequent differences in the outcome of vocational rehabilitation. The office with the lowest rate of sick-listing periods exceeding 1 year, and a with a high frequency of employment training, showed the highest degree of work resumption and the lowest pension rate after vocational rehabilitation [12].

A study in the county of Jämtland in 1992-1993 compared 59 employed and 59 unemployed matched sick-listed persons with back, neck or shoulder conditions identified from administrative registers. The potential need for rehabilitation among unemployed individuals was not investigated to the same extent as among employed individuals, but when the process had started there were no significant differences between unemployed and employed persons in the service they received [22].

Finally, Hetzler et al. [23] compared two cohorts of individuals on long-term ( $>60$ days) sick leave: 8092 persons in 1990-1993 and 4007 persons in 2001-2002 with regard to rehabilitation. The prevalence of rehabilitation increased from 8.3 in 1990 1993 to $17.3 \%$ in $2001-2002$ and medical rehabilitation increased from 1.2 to $21 \%$ over the same period. In 2001-2002, there were differences in selection into programmes by age and income group: individuals aged 36-45 years were most likely, and persons aged over 55 years were least likely, to receive rehabilitation. Those sick-listed by a company doctor were more likely to receive rehabilitation. Individuals in the second lowest income group were most likely, and those in the highest income group were least likely, to receive rehabilitation [23].

\section{Are there differential outcomes of rehabilitation?}

In relation to review question 2 on differential outcomes of rehabilitation, seven studies were identified for inclusion in the review (see Table II). 


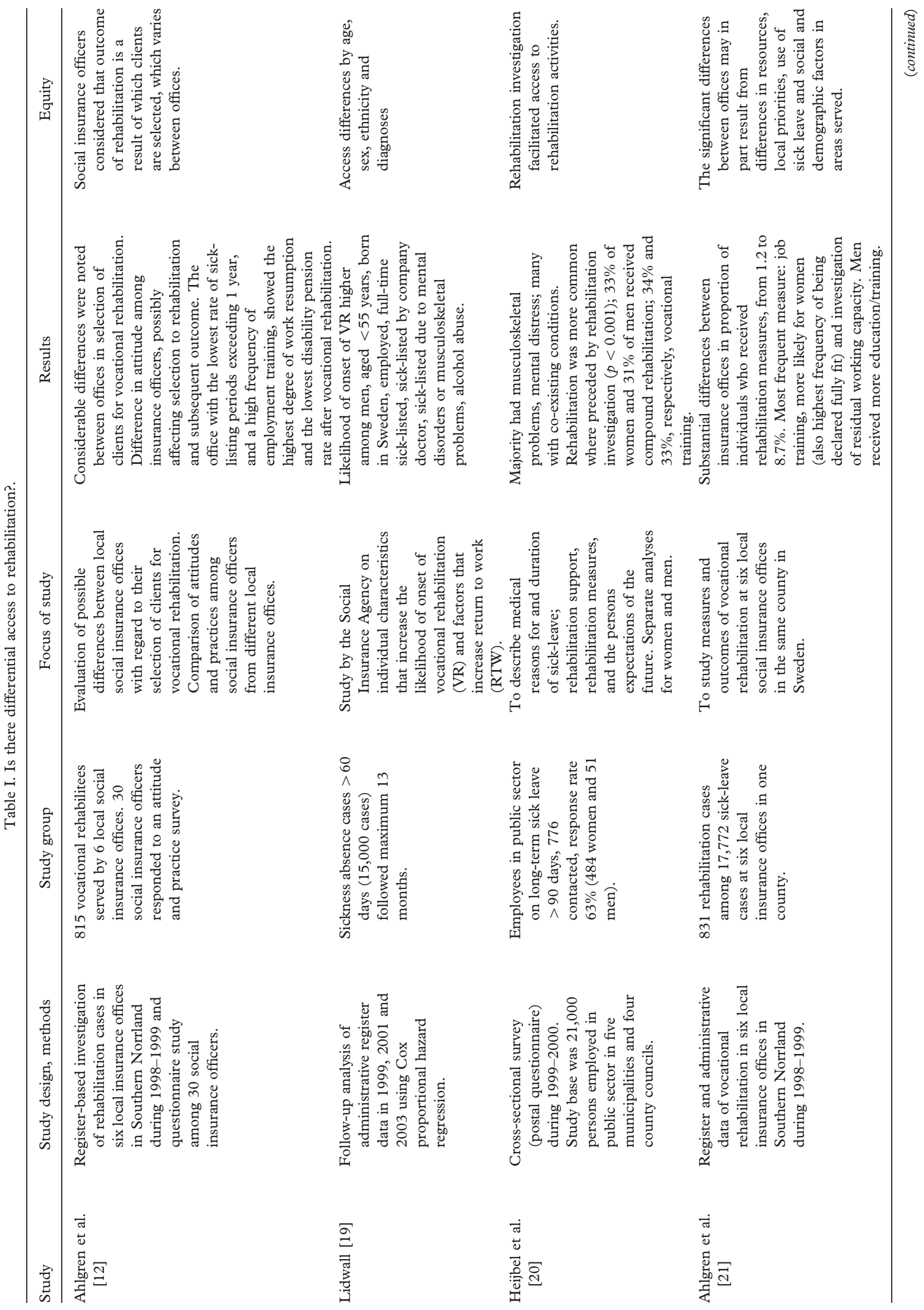




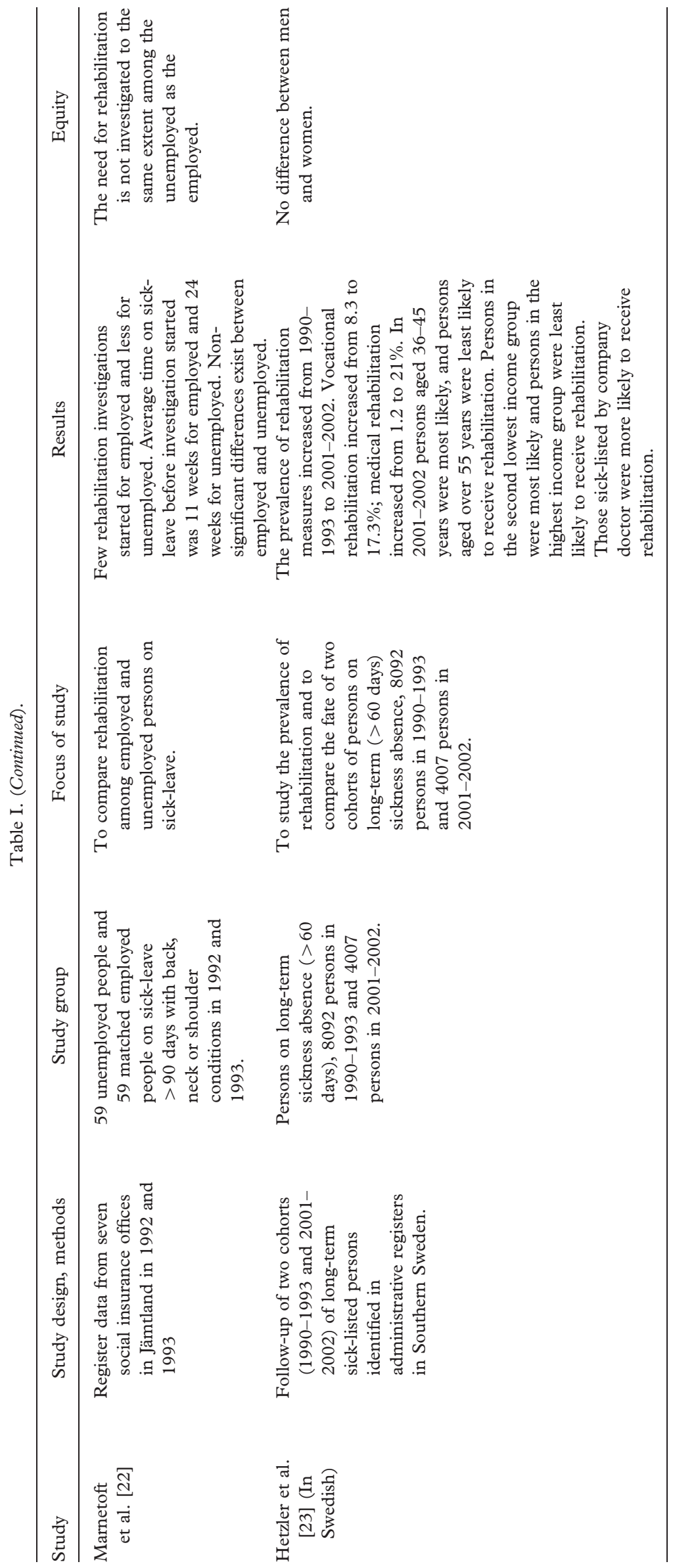


None of the studies had explicit equity objectives, but their results addressed the review question implicitly. There was some evidence of differential outcomes by socio-demographic and health condition characteristics of participants, but in many cases it was not possible to ascertain the extent to which the outcome was influenced by differential selection.

In the register-based study of 15,000 individuals on long-term ( $>60$ days) sick leave, the likelihood of return to work following vocational rehabilitation was higher among men, the age group $<55$ years (even more at age $<40$ years), born in Sweden, employed or self-employed, sick-listed due to problems in the respiratory or digestive system, not abusing alcohol, not on waiting list for medical treatment, with no previous long-term sickness absence period. Vocational rehabilitation increased the rate of return to work on average by $8 \%$ in the years 1999, 2001 and 2003, to a lesser degree in 2001 and 2003. The positive effects on employment were strongest for work training and vocational education, and for men and younger people in general [19].

It has been suggested that people who are immigrants suffering from long-term pain do not benefit to the same extent as people born in Sweden from the rehabilitation offered. However, a 1-year and a 3-year follow-up of an 8-week rehabilitation programme attended by 67 individuals with persistent non-malignant pain [27] showed that immigrants can benefit to the same extent as native Swedes concerning return-to-work rate. After 1 year, 17 out of 30 immigrants (57\%) had returned to work or work-related activities compared with 25 out of 37 native Swedes (68\%). After 3 years, the corresponding rates were 13 out of $27(48 \%)$ and 16 out of 32 $(50 \%)$, respectively. These differences were not statistically significant. However, participants' prediction of their ability to return to work was significantly higher among the non-immigrants. At the start of the programme 28 out of 30 (93\%) immigrant participants compared with 25 out of 37 $(68 \%)$ native Swedes $(p=0.023)$ thought it would be hard or very hard to return to work after the rehabilitation programme. A larger proportion of immigrants $(83 \%)$ than native Swedes $(49 \%)$ were classified as blue-collar workers at the start of the programme. In logistic regression analyses of prognostic factors for return to work at 1-year and 3-year follow-up, there were no statistically significant differences in odds ratios with regard to length of sick leave before rehabilitation, between immigrants and native Swedes, between blue-collar workers and white-collar workers or between males and females. At the 3-year follow-up, 6 of the immigrants and 7 of the native Swedes had changed their professions. Half of the immigrants were or had been employed as cleaners, but had other professions that they, for different reasons, could not practice in Sweden [27].

A cohort study [23] of 8092 persons in 1990-1993 and 4007 persons in 2001-2002 reported the length of the sick leave spell was the strongest predictor for return to work. Those with a sick leave spell of less than 3 months were much more likely to return to work than those with longer sick leave, who were more likely to receive disability pension. Rehabilitation was less successful in 2001-2002 than in 19901993. The overall proportion returning to work were $68.2 \%$ in $1990-1993$ and $59.8 \%$ in $2001-2002$. The unemployed had lower rates of return to work, as did those sick-listed by company doctors. There was evidence of differential outcome by income: the rates of return to work were $34.3 \%$ among low-income earners and $67.9 \%$ among high-income earners [23]. For three typical cases (young adult with depression, older person with back problems and low-income earner with back problems), the rate of return to work was actually lower among those who had received rehabilitation, compared with those who had not received rehabilitation [23]. This may in part reflect selection mechanisms in that the more severe cases are those who receive rehabilitation, while the less severe cases do not need or receive rehabilitation in order to return to work. However, the authors also comment that this may reflect changes in the labour market, as persons on long-term sick leave have experienced increasing difficulties finding work after rehabilitation over the study period [23].

A study that investigated whether large investments in vocational rehabilitation made in Sweden during the 1990s had improved the return-to-work rates for young employees found that intensive rehabilitation efforts increased rates for both men and women with musculoskeletal disorders, but that men benefited more than women. The authors discussed possible reasons for this, suggesting that women's occupations entail lower decision latitude and lesser possibilities for adjustments. In addition, more women came back to shorter working hours after rehabilitation, possibly because women do more domestic work. Men were more often referred to specialist care, suggesting that men's conditions were taken more seriously than women's conditions [28].

In a follow-up study of work resumption among 815 previous sick-leavers granted vocational rehabilitation [24], 52.4\% had attained full working capacity; but after 2 years this had decreased to $37.4 \%$. The clients with the best chances of being in work 2 years after they completed vocational rehabilitation were those with shorter sick leave, who had been selected for job training, were aged 16-29 years and were employed in industry. A related study found that among employed persons the rate of return to work was $47.4 \%$, compared with 


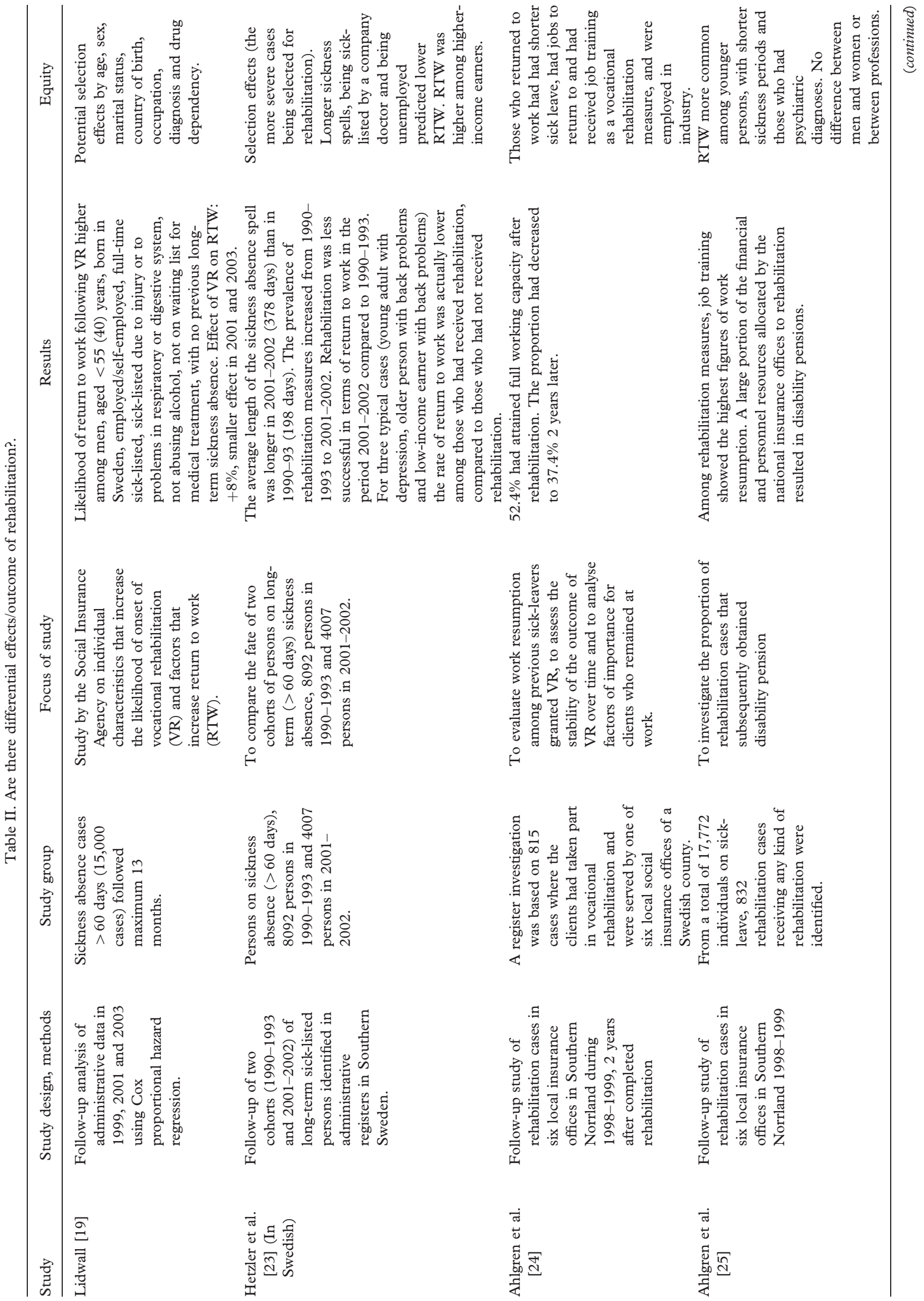




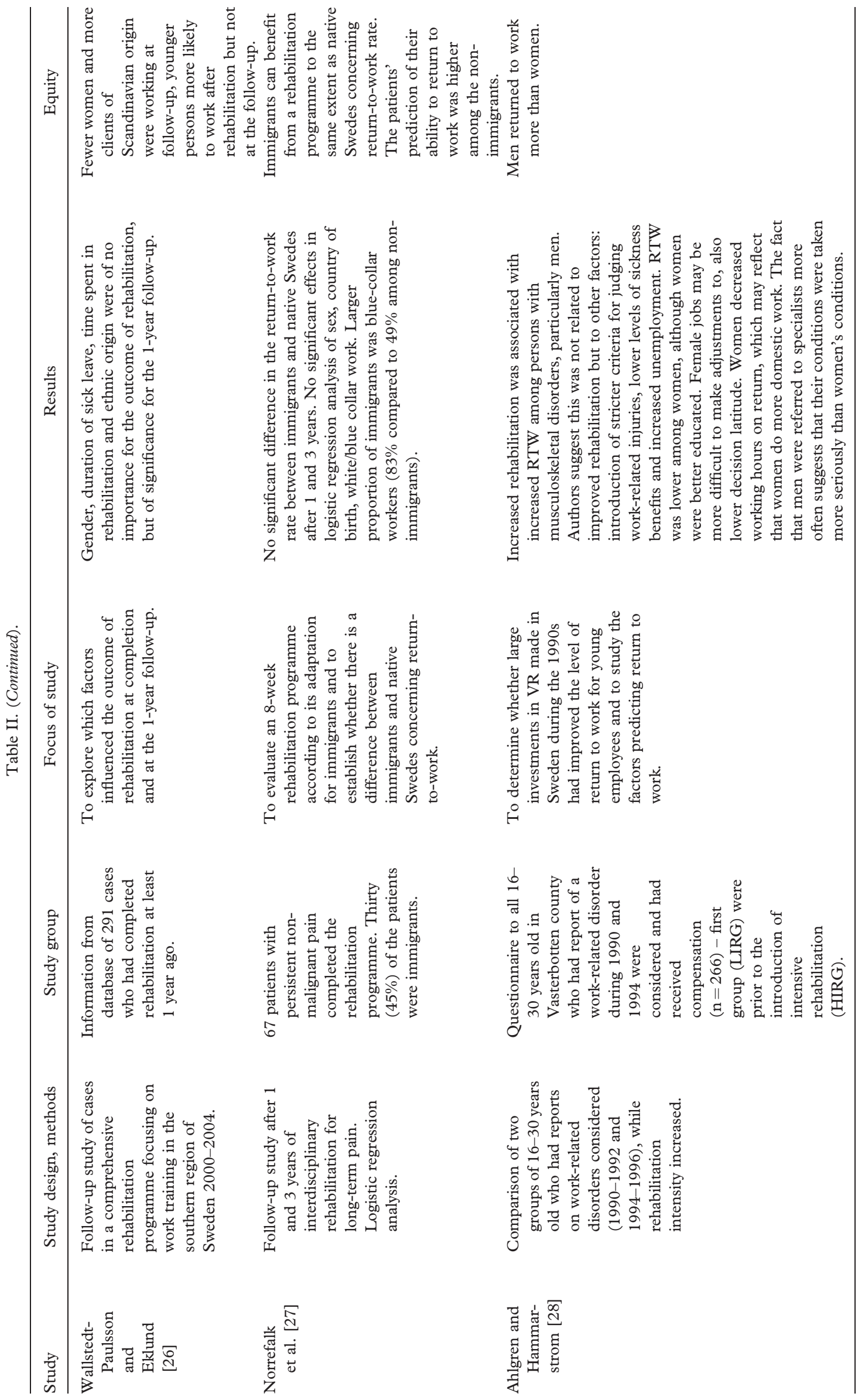


$23.8 \%$ among those unemployed. Job training resulted in the highest rates of work resumption. Investigation of residual working capacity, on the other hand, often preceded disability pension. The authors suggested that investigation of residual working capacity, although counted as a vocational rehabilitation measure, was to be seen more as a verification of a need for disability pension and that this could be better handled within the health care system rather than in vocational rehabilitation [25].

Another study followed-up 291 clients who had participated in a comprehensive rehabilitation programme focusing on work training, upon completion of the programme and 1 year after completion [37]. Upon completion, $69 \%$ had work capacity but the majority of these (109 out of 202) were unemployed. At the 1-year follow-up 43 out of 109 (39\%) unemployed individuals were working, but 40 were attending further rehabilitation or assessment. Of those 93 working upon completion of the programme, 71 remained in work after 1 year. After 1 year, a total of 120 out of 291 individuals were attending further rehabilitation or assessment. Gender, duration of sick leave, time spent in rehabilitation and ethnic origin were of no importance for the outcome of rehabilitation, but of significance for the 1-year follow-up. More men and fewer women than expected were working at the 1-year follow-up, younger persons were more likely to work, but there was no statistically significant difference in employment upon completion and after 1 year between those who were and who were not employed before the rehabilitation programme. Educational background was not related to outcome immediately after rehabilitation or at the 1-year follow-up. Selfratings were done at the 1-year follow-up, regarding the influence of one's own situation, available support from family and friends and need of societal support. Persons of non-Scandinavian origin reported significantly less influence on their own situation and significantly more need of societal support [26].

\section{Discussion}

The review found no studies that had the explicit aim of measuring differential access or outcomes of rehabilitation. Nevertheless, 11 studies were identified that contained relevant evidence to address the review questions. Regarding differential access, two observations can be made from the studies. Relatively few long-term sick-listed individuals receive the required rehabilitation investigation - irrespective of their characteristics and despite it being a legal requirement nationally. So, access is poor for everyone - the policy is not being implemented as it was intended. As a consequence, relatively few go on to receive vocational rehabilitation. Poor access to rehabilitation implies extended periods of sick leave and to the detriment of the individual, the employer and the society.

Second, there is evidence (albeit patchy) of biased selection into vocational rehabilitation - leading to differential access by occupational class, health condition, gender and length of sick leave. In some cases, this goes against the spirit of the national framework law, while in other cases it may be justified in the spirit of matching programmes to specific needs. There were also indications in the studies reviewed that selection may operate in different ways. Less severe cases may be expected to return to work without rehabilitation; more severe cases, even if selected for rehabilitation, may have a poorer prognosis of return to work. Certain measures under the umbrella of rehabilitation (such as investigation of work ability) may be directed to particularly severe cases, as a step towards disability pension.

These conclusions have implications for how the national policy is implemented. That the lack of coordination between different actors and delay of onset of rehabilitation may be detrimental to the individual waiting for vocational rehabilitation has been previously recognised in other studies and government investigations $[6,29]$. The policy changes implemented in 2008 aimed to address this [15]. Specific matching of vocational rehabilitation to the needs of the individual and careful selection of which individuals may benefit from which type of intervention may increase the effectiveness. However, there is a danger that this may lead to creamskimming [30,31] - selecting the easier cases to increase chances of successful return to work - and this needs to be guarded against.

Regarding the second review question, again, very few studies had the explicit aim of assessing the differential impact of vocational rehabilitation. Nevertheless, it was still possible to gain relevant evidence from several studies that recorded outcomes by socio-demographic or health conditions, and all of these demonstrated that some differential impact was occurring. Differential impacts included a greater likelihood of return to work among men compared with women, younger people, those born in Sweden, those with no previous record of longterm sickness absence and for the employed compared with unemployed. More studies investigating differential impact are needed. In addition, any assessment of the evidence needs to consider the degree and nature of selection of participants into the vocational rehabilitation programmes to understand and properly interpret the impact results. In some circumstances, it may be appropriate to have 
different interventions for different groups in the population. It will also depend on what the aims of the overall policy are - if it is to 'level-up' the chance of return to work for the people in the most difficult circumstances, then more intensive efforts (e.g. training and education) may be justified to help those groups. However, such selection and differential treatment should be based on sound reasons and guided by evidence of differential need and differential effectiveness.

Our conclusions highlight the need for this kind of equity analysis on population-wide policies, and the assessment of differential access and impact to be an integral part of any evaluation of policies and interventions. Evaluators of effectiveness of such interventions in the social policy field often have no control over the selection of participants into programmes. Nonetheless, the evaluations should not be automatically judged by systematic reviews as fatally flawed because of biased selection into programmes (as trials with biased selection would be in systematic reviews in health care). What is essential is the assessment of the degree of biased selection, as part of the overall evaluation of how a social welfare policy or intervention is operating.

The selection of specific groups into certain vocational rehabilitation programmes could potentially be an instrument for improving equitable outcomes, in the sense that groups with conventional rehabilitation may still have problems returning to their previous tasks and may need more extensive measures, such as retraining, to acquire new skills for other types of jobs. Studies are needed for the outcome of different types of specific rehabilitation interventions. In addition, the outcomes should be analysed in relation to diagnoses - people with musculoskeletal diagnoses may be less successful in coming back to manual jobs than to tasks that do not involve heavy physical work. Unemployed persons are at particular risk, both of not getting access to rehabilitation and of not having successful outcomes when they do get rehabilitation. This suggests that particular attention is warranted to unemployed sicklisted persons and that there must be appropriate jobs to return to.

\section{Additional factors of importance to the success of rehabilitation}

Other factors not assessed in this study have been found to be important for successful rehabilitation, including shortcomings in the current organisation and administration of long-term sickness cases.

The day-to-day implementation of policies is important. In a survey of 5271 administrators at the Social Insurance Agency, less than half of the respondents were fully aware of laws and regulations governing the rights of sick-listed persons to vocational training [32], which is likely to affect how clients are handled. Such difference in attitudes and practices among social insurance officers was also demonstrated by Ahlgren et al. [12] in our review and may have implications for differences in how clients are selected for rehabilitation, which in turn may affect the outcome of rehabilitation. Holding a coordination meeting (as recommended) among different rehabilitation actors for persons on longterm sick leave increased the probability five-fold of an active rehabilitation measure being initiated, and doubled the probability that adaptation at the workplace would be started. However, it may also accelerate the process towards disability pension [33]. There may also be conflicting goals between agencies involved in rehabilitation, as indicated in one study, resulting in unemployed sick-listed persons getting low priority for rehabilitation efforts [34]. Furthermore, as found in a 2008 study, different professionals may have qualitatively different views on clients, leading to 'unequal encounters' and differences in opportunities for rehabilitation [35]. Several government investigations have pointed to the need for better coordination in rehabilitation, and even proposed a new, single agency [29], though these changes have not yet been implemented.

In addition, the workplace is important for rehabilitation and successful return to work. In one study, private companies with few individuals on sick leave showed a more distinct structured plan for how to deal with rehabilitation than companies with more sick-listed employees. The most important factors for return to work among individuals on sick-leave were motivation to return and a decrease of the symptoms that caused the sickness absence [36]. Work organisation is also important for return to work. Opportunities to adjust one's work to one's state of health by choosing among work tasks and deciding about work pace and working hours increased the likelihood to return to work after long-term sickness absence in a study of white-collar employees [37].

The diagnosis of the patient is also important for rehabilitation. A 2009 report from multidisciplinary investigations of long-term sickness absentees to clarify medical conditions showed a high prevalence of co-morbidity of psychiatric and somatic diagnoses. Patients were examined by specialists in psychiatry, orthopaedic surgery and rehabilitation medicine. About $80 \%$ had more than one diagnosis, the majority had a psychiatric diagnosis and $55 \%$ had that in combination with a somatic diagnosis. The risk of having a psychiatric diagnosis was higher among men and unemployed people. This indicates the importance of clarifying the diagnosis as well as 


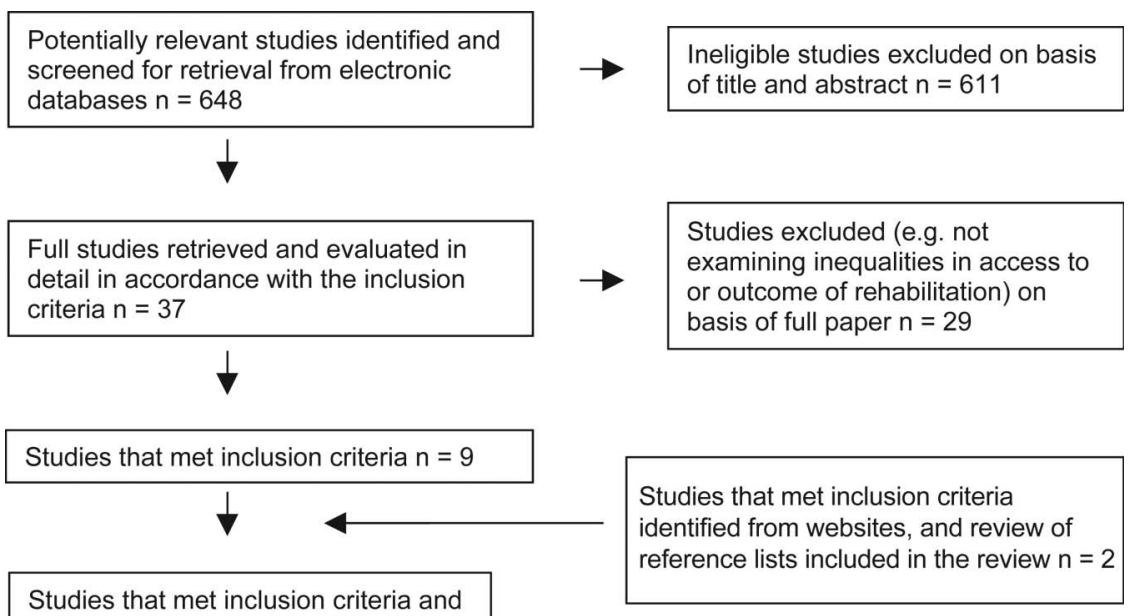

included in the review $n=11$

Figure 1. Flow chart for searches and study selection, equity in vocational rehabilitation, 1990-2009.

the social circumstances of long-term sickness absentees [38].

\section{Problems and pitfalls in studying social differentials in access to and effects of rehabilitation}

One basic issue for the study of effectiveness of vocational rehabilitation programmes is that of selection. Selection may operate in two ways. On the one hand, more severe cases that do not get better spontaneously may be more likely to be subjected to rehabilitation programmes [23]. Conversely, there have been reports of cream-skimming, where cases more likely to return to work are selected for the programmes [30,31] Another issue pertaining to the Swedish studies is the terminology of vocational rehabilitation. This wide concept may include many different interventions, some of which (e.g. investigation of work ability) may be more appropriately seen as part of the assessment for receiving disability pension than as active work-related rehabilitation. Lumping together these different interventions may confuse the interpretation of results. The measure of effect of rehabilitation also varies. Some studies measure in reduced number of sickness absence days, reduced number of sickness absence spells, reduced costs, increased number reporting well, and finally rates of return to work. Another (negative) outcome is disability pension. Some studies have noted that successful rehabilitation may not automatically translate into return to work, but that it will depend on the labour market situation. Interaction with the local labour market may further colour both selection into rehabilitation and outcome in terms of return to work, as suggested in some studies [12,23]. In addition, interventions directed towards altering the work environment may be important but have not been addressed in this review. Finally, most of the studies reviewed here did not have a control group, which further limits the assessment of the effectiveness of interventions.

Vocational rehabilitation and other interventions to enable people with chronic illness to remain in or return to the labour market is a key policy area involving several sectors of society. It is important that it is given due emphasis, as it has major significance for the individual, the workplace and society as a whole [1]. Further and better-quality studies of interventions that include equity assessments both of access and outcomes are needed in this area, in order to guide more effective policymaking.

\section{Declaration of interest}

$\mathrm{BB}$ and LN were partly funded by the Swedish Council for Working Life and Social Research (FAS 2009-0701) and the Nordic Council. SC and MMW carried out this research as part of the work of the Public Health Research Consortium, which is funded by the Department of Health Policy Research Programme. The views expressed in the publication are those of the authors and not necessarily those of the English Department of Health or the other funders.

\section{References}

1. OECD. Sickness, disability and work. Keeping on track in the economic downturn. Background paper. High-level Forum, Stockholm 14-15 May 2009. Internet. 2009. Electronic citation. http://www.oecd.org/els/disability/stockholmforum. Last accessed June 2009. 
2. Government Offices of Sweden. Increased health in working life. Internet. 2004. Electronic citation. http://www.regeringen.se/sb/d/2777. Last accessed August 2004.

3. Burström B, Whitehead M, Lindholm C, Diderichsen F. Inequality in the social consequences of illness: how well do people with long-term illness fare in the British and Swedish labor markets? Int J Health Serv 2000; 30:435-451.

4. Burström B, Holland P, Diderichsen F, Whitehead M. Winners and losers in flexible labor markets: the fate of women with chronic illness in contrasting policy environments-Sweden and Britain. Int J Health Serv 2003; 33:199217.

5. Bambra C, Whitehead M, Hamilton V. Does 'welfare-towork' work? A systematic review of the effectiveness of the UK's welfare-to-work programmes for people with a disability or chronic illness. Soc Sci Med 2005; 60:1905-1918.

6. Bergendorff $\mathrm{S}$. Rehabilitering - ett långt lidandes historia. Samtal om socialförsäkringen $\mathrm{nr}$ 10. (Rehabilitation - the history of a long suffering.) Socialförsäkringsutredningen, Socialdepartementet, 2006. (In Swedish).

7. Ekberg K. Rehabilitation to work. In: Gustafsson RÅ, Lundberg I, editors. Worklife and health in Sweden. Stockholm: National Institute for Working Life; 2004. pp 389-406.

8. Eklund $\mathrm{M}$, Lidwall $\mathrm{U}$, Marklund $\mathrm{S}$. Hur fungerar den arbetslivsinriktade rehabiliteringen? (How does vocational rehabilitation work?) In: Marklund S, Bjurvald M, Hogstedt C, Palmer E, Theorell T, editors. Den höga sjukfrånvaron problem och lösningar [in Swedish]. (The high sickness absence - problems and solutions.). Stockholm: Arbetslivsinstitutet; 2005. pp 271-301.

9. Delander L, Nyberg E. Effektutvärdering av arbetslivsfonden. (Effect evaluation of the Working Life Fund.). Stockholm: Arbetslivsfonden 1995. (In Swedish).

10. SOCSAM - försök med politisk och finansiell samordning. En slutrapport, Finansiell samordning 2001:1. (SOCSAM - trials with political and financial co-ordination. A final report. Financial co-ordination.). Stockholm: National Social Insurance Board and the National Board of Health and Welfare; 2001. (In Swedish).

11. Ekholm J, Schüldt Ekholm K. Vocational rehabilitation: the Swedish model. In: Gobelet C Franchignoni F, editors. Vocational rehabilitation. Paris: Springer; 2006. pp 389-394.

12. Ahlgren A, Bergroth A, Ekholm J, Schült Ekholm K. Selection of clients for vocational rehabilitation at six local social insurance offices: a combined register and questionnaire study of rehabilitation measures and attitudes among social insurance officers. J Rehabil Med 2008; 40:178-184.

13. Frolich $M$, Hashmati A, Lechner M. A microeconometric evaluation of rehabilitation of long-term sickness in Sweden. J App Econometrics 2004; 19:375-396.

14. Selander J, Marnetoft S-U, Bergroth A, Ekholm J. Return to work following vocational rehabilitation for neck, back and shoulder problems: risk factors reviewed. Disabil Rehabil 2002; 24:704-712.

15. Government Offices of Sweden. Effective return to work. Ministry of Health and Social Affairs. Internet. 2009. Electronic citation. http://www.sweden.gov.se/sb/d/2028/a/ 111365. Last accessed May 2009.

16. Marnetoft S-U, Selander J, Bergroth A, Ekholm J. Vocational rehabilitation - early versus delayed. The effect of vocational rehabilitation compared to delayed vocational rehabilitation among employed and unemployed long-term sick listed people. Int J Rehabil Res 1999; 22:161-170.

17. Ahlgren A, Broman L, Bergroth A, Ekholm J. Disability pension despite vocational rehabilitation? A study from six social insurance offices of a county. Int J Rehabil Res 2005; 28:33-42.
18. OECD. Sickness, disability and work: Breaking the barriers. SWEDEN: will the recent reforms make it?. Internet. 2009. Electronic citation. http://www.oecd.org/dataoecd/2/59/ 42265699.pdf. Last accessed June 2009.

19. Lidwall U. Försäkringskassan och arbetslivsinriktad rehabilitering- aktiva åtgärder och återgång $i$ arbete. (The Swedish Social Insurance Agency - active vocational rehabilitation measures and return to work.). Försäkringskassan; Analyserar 2006:10. (In Swedish).

20. Heijbel B, Josephson M, Jensen I, Vingård E. Employer, insurance, and health system response to long-term sick leave in the public sector: policy implications. J Occup Rehabil 2005; 15:167-176.

21. Ahlgren A, Bergroth A, Ekholm J. Work resumption or not after rehabilitation? A descriptive study from six social insurance offices. Int J of Rehabil Res 2004; 27:171-180.

22. Marnetoft S-U, Selander J, Bergroth A, Ekholm J. The unemployed sick-listed and their vocational rehabilitation. Int J of Rehabil Res 1997; 20:245-253.

23. Hetzler A, Melén D, Bjerstedt D. Sjuk-Sverige. Försäkringskassan, rehabilitering och utslagningen från arbetsmarknaden. (Sick Sweden. The Social insurance office, rehabilitation and exclusion from the labour market.). Stockholm; Brutus Östlings förlag Symposion; 2005. (In Swedish).

24. Ahlgren A, Bergroth A, Ekholm J, Schüldt K. Work resumption after vocational rehabilitation: a follow-up two years after completed rehabilitation. Work 2007; 28:343-354

25. Ahlgren A, Broman L, Bergroth A, Ekholm J. Disability pension despite vocational rehabilitation? A study from six social insurance offices of a county. Int J Rehabil Res 2005; 28:33-42.

26. Wallstedt-Paulsson E, Eklund M. Outcome of work rehabilitation for people with various disabilities and stability at a one-year follow-up. Work 2008; 31: 473-481.

27. Norrefalk JR, Ekholm J, Borg K. Ethnic background does not influence outcome for return-to-work in work-related interdisciplinary rehabilitation for long-term pain: 1- and 3-year follow-up. J Rehabil Med 2006; 38:87-92.

28. Ahlgren C, Hammarstrom A. Has increased focus on vocational rehabilitation led to an increase in young employees' return to work after work-related disorders? Scand J Pub Health $1999 ; 27: 220-227$.

29. SOU. En handlingsplan för ökad hälsa i arbetslivet. Slutbetänkande från Utredningen om handlingsplan för ökad hälsa i arbetslivet. (An action plan for better health in work life.) Socialdepartementet; Statens offentliga utredningar SOU 2002:5. (In Swedish).

30. Aakvik A. Bounding a matching estimator: the case of a Norwegian training program. Ox Bull Econ Stat 2001; 63:0305-9049.

31. Aakvik A. Estimating the employment effects of education for disabled workers in Norway. Empir Econ 2003; 28:515-533.

32. Ujiii E. Handläggarnas attityder till rehabiliterande åtgärder och insatser samt lagar och regler. (Social insurance administrators' attitudes towards different rehabilitation measures and legislation.) Försäkringskassan; Analysera 2006:21. (In Swedish).

33. Tollin P. Vad händer efter avstämningsmötet? (What happens after the initial status meeting?) Försäkringskassan; Analysera 2007:3. (In Swedish).

34. Eriksson UB, Engstrom LG, Starrin B, Janson S. Falling between two stools; how a weak co-operation between the social security and the unemployment agencies obstructs rehabilitation of unemployed sick-listed persons. Disabil Rehabil 2008; 30:569-576.

35. Sandstrom U, Stålsby Lundborg C, Axelsson R, Holmström I. Variation in views on clients in interprofessional work for 
vocational rehabilitation in Sweden. J Interprof Care 2007; 21:479-489.

36. Vingård E, Waldenström $M$, Bentsson $F$, Svartengren $M$, Ekenvall L, Ahlberg G, and the HoF-study group. Långtidssjukskrivning, rehabilitering och återgång $i$ arbete - processer och resultat hos företag inom privat sektor. (Long-term sickleave, rehabilitation and return to work - processes and results among companies in the private sector.) Hälsa och framtid delstudie 4, 2007. (Health and Future, study 4, 2007). Internet. 2007. Electronic citation. www.folkhalsoguiden.se/ halsaochframtid. Last accessed June 2009. (In Swedish).

37. Johansson G, Lundberg O, Lundberg I. Return to work and adjustment latitude among employees on long-term sickness absence. J Occup Rehabil 2006; 16:185-195.

38. Salmi P, Svedberg P, Hagberg J, Lundh G, Linder J, Alexanderson K. Multidisciplinary investigations recognize high prevalence of co-morbidity of psychiatric and somatic diagnoses in long-term sickness absentees. Scand J Publ Health 2009 ; 37:35-42.

\section{Appendix. Electronic search strategy}

The following search terms have been used in the electronic search:

- Population: disabilit* OR disabled OR chronic ill* OR chronic sick ${ }^{\star}$ OR LLTI OR longstanding illness OR long-term sick ${ }^{\star}$ OR longterm ill* OR permanent sickness

- Employment status: work OR job^ OR vocation` OR labour OR labor OR unemploy^ OR employment

- Treatment: rehabilitat* OR welfare-to-work OR back-to-work OR welfare-to-work OR return-to-work OR training OR retraining OR skills OR advice OR counselling
- Search limitations used: published 1990-2009, Sweden, English or Swedish language.

The following electronic databases were searched for relevant studies published between 1990 and 2009 (number of hits indicated in parentheses): PubMed (228), PsycINFO (49), Cochrane (123), Cinahl (93), SveMed+ (17) and 'ERIC, CSA, PILOTS Database, Social Services Abstracts, Sociological Abstracts' (138).

The following Swedish websites were searched using the Swedish search term 'arbetslivsinriktad rehabilitering' (vocational rehabilitation). For each website the result (number of hits - relevant studies) is indicated: Karolinska Institutet (www.ki.se) (440); National trade union (www.lo.se) (33-0); The National Board of Health and Welfare (www.socialstyrelsen.se) (86-0); The Swedish Social Insurance Agency (www.forsakringskassan.se) (43-2); The Equality Ombudsman in Sweden (www.do.se) (00 ); Swedish Council for Working Life and Social Research (www.fas.forskning.se) (8-0); The Swedish Handicap Institute (www.hi.se) (3-0); Institute for labour market policy evaluation (www.ifau.se) (150 ); Government offices of Sweden (www.regeringen.se) (21-0); Stockholm Centre for Public Health, within Karolinska Institutet and Stockholm County Council (www.folkhalsoguiden.se) (18-0); Insurance company supporting projects improving work environment (www.afaforsakring.se, www.suntliv.nu, www.arbetsmiljoupplysningen.se) (48-0); Swedish National Institute of Public Health (www.fhi.se) (16-0). 